\title{
Distribution and activity patterns in an intertidal grazer assemblage: influence of temporal and spatial organization on interspecific associations
}

\author{
Moisés A. Aguilera ${ }^{1,2, *}$, Sergio A. Navarrete ${ }^{1}$ \\ ${ }^{1}$ Estación Costera de Investigaciones Marinas, Las Cruces, and Center for Advanced Studies in Ecology and Biodiversity, \\ Pontificia Universidad Católica de Chile, Casilla 114-D, Santiago, Chile \\ ${ }^{2}$ Centro de Estudios Avanzados en Zonas Áridas (CEAZA), Facultad de Ciencias del Mar, Universidad Católica del Norte, \\ Larrondo 1281, Coquimbo, Chile
}

\begin{abstract}
In consumer assemblages, the organization of individual foraging behavior, as well as spatial distribution, can largely determine environmental risks, and the intensity of intra- and interspecific interactions. We characterized distributional and behavioral patterns of the most common benthic grazers coexisting in the rocky shores of central Chile: the chiton Chiton granosus, the pulmonate limpet Siphonaria lessoni, the scurrinid limpet Scurria araucana and the keyhole limpet Fissurella crassa. C. granosus and F. crassa were strictly nocturnal foragers whereas S. lessoni foraged during daytime. Most $S$. araucana individuals foraged at night, but daytime foraging was also common. The spatial distribution at resting varied from aggregated for C. granosus and S. lessoni to a more dispersive pattern for F. crassa and S. araucana. C. granosus dispersed slightly from aggregation when foraging whereas $S$. lessoni foraged in tight conspecific aggregations. Foraging excursions varied from over $60 \mathrm{~cm}$ in $F$. crassa to less than $7 \mathrm{~cm}$ in $S$. araucana. Homing behavior ranged from extreme fidelity in F. crassa to low fidelity in $S$. lessoni. Positive associations were observed between C. granosus and F. crassa during resting and foraging whereas negative associations were observed between these species and S. lessoni. These general patterns varied little between 2 sites separated by a few kilometers. Interspecific competition might be important in structuring this guild, but it may affect only some species pairs. Direct interference in the use of shelter or while foraging, rather than food exploitation, seems the most likely mechanism. The marked differences in individual behavior among species, despite ample diet overlap, might translate into different functional effects, which should be explored in future experiments.
\end{abstract}

KEY WORDS: Activity rhythm · Foraging behavior - Interspecific association · Molluscan grazer · Spatial distribution

Resale or republication not permitted without written consent of the publisher

\section{INTRODUCTION}

Theoretical and experimental studies on animal movement and activity patterns have been developed for a variety of species in an attempt to explain and/or empirically relate the spatial distribution of mobile animals to their food resources, environmental conditions, interspecific interactions and, more recently, ecosystem function (Schmitz 2008). A general finding is that, beyond phylogenetically constrained ('hard-wired') responses (see Webb et al. 2002), landscape heterogeneity as well as long- and short-term changes in resource distribution can influence the organization of foraging in herbivores (see Fletcher \& Underwood 1987, Legendre \& Fortin 1989, Chapman \& Underwood 1992, Rossi et al. 1992, Tilman \& Kareiva 1997). But although behavior is a highly labile trait, different species typically exhibit characteristic and contrasting 
behavioral patterns (Palmer 1995). Thus, beyond individual and within-species variation, species can adopt different strategies to cope with the same general landscape of environmental and resource (e.g. food, shelter) heterogeneity (Pulliam 1989, Chapman \& Underwood 1992, Legendre et al. 1997, Schmitz 2009). These behavioral patterns will in turn have effects on predation risks perceived by individuals, on the spatial patterns they exert on their resources, and on intraand/or interspecific interactions within their guild.

Within guilds of grazing mollusks, which commonly are the most diverse taxa in temperate and tropical rocky shores (Lubchenco \& Gaines 1981, Hawkins \& Hartnoll 1983, Rivadeneira et al. 2002, Coleman et al. 2006), strikingly different activity and movement patterns have been observed among coexisting species (e.g. Branch 1981, Hawkins \& Hartnoll 1983 for review). These behavioral repertoires can generate differential patterns of distribution and abundance in the guild (Underwood \& Chapman 1996, Chapman 2000, Olabarria et al. 2002) and account for differences in specific grazing impacts, which cannot be inferred from their diets alone (Branch 1981, Chapman \& Underwood 1992, Jenkins et al. 2005, Coleman et al. 2006). Comparatively few studies have evaluated how activity and movement patterns relate to intra- and interspecific spatial distributions and how these patterns vary when individuals are actively foraging or resting. This type of information can shed light on the biotic and/or abiotic processes that structure these assemblages and provide the basis for elaborate hypotheses about the role of species in ecosystem function (e.g. Schmitz 2009). For instance, species that present different foraging activities (e.g. diurnal versus nocturnal) are less likely to compete for shelter or engage in direct interference when grazing (Carothers \& Jaksic 1984, Loreau 1992), although they could still compete for a common food resource (Jaksic 1982, Carothers \& Jaksic 1984). Conversely, a species could compete and interfere with one species while foraging and with a different species or set of species while seeking shelter. Thus, the degree of spatial or temporal overlap during resting and foraging conditions within the guild can be very informative about interspecific interaction strength between species pairs, assemblage structure and the consumption pressure the species exert on their prey.

The coast of central Chile is characterized by a semidiurnal tidal regime of $\sim 1.70 \mathrm{~m}$ amplitude and the predominance of rocky shores directly exposed to wave action (Castilla 1981, Finke et al. 2007). Approximately 10 to 24 species comprise the intertidal mollusk grazer assemblage along the coast of Chile (Rivadeneira et al. 2002), with roughly 7 to 9 common species coexisting locally at mid to high intertidal lev- els (Otaíza \& Santelices 1985, Santelices et al. 1986). Extensive analysis of stomach contents and grazer abundance conducted at a site in central Chile showed ample overlap in the diet of the most common species (Santelices et al. 1986), with all species consuming epilithic, green and crustose (calcareous and fleshy) algae. Slight differences in diet between species were partly related to morphological differences in their radula (as suggested by Steneck \& Watling 1982), but also to habitat and behavioral differences (Santelices et al. 1986). Slight differences in diet, together with large differences in body size and biomass, can lead to marked differences in the impact these species can have on algal assemblages (see Wieters et al. 2003, Aguilera \& Navarrete 2007). Furthermore, previous studies (e.g. Santelices et al. 1986) and field observations suggest patchiness in the micro-scale $(\mathrm{cm})$ spatial distribution of some species, apparently related to the spatial structure of the habitat. Further research on grazer diets conducted by Camus et al. (2008) at multiple sites in northern Chile has highlighted the high frequency $(>40 \%)$ at which invertebrate items are included in the diet of most grazer species (see also Otaíza \& Santelices 1985, Aguilera 2005, Aguilera \& Navarrete 2007), including a high representation of individuals of other herbivores within the same guild (Aguilera 2005, Camus et al. 2008). This high level of intraguild predation (sensu Polis \& Holt 1992), together with low levels of cannibalism (Camus et al. 2008), suggest that interspecific interactions within the grazer guild might be more important and more complex than previously envisioned.

In the present study, we examined the spatial patterns of distribution and activity of the 4 most common grazer species present in central Chile, which inhabit the mid-low to the high intertidal zone (i.e. 0.5 to $3.0 \mathrm{~m}$ ), in order to evaluate the spatial and temporal (i.e. behavioral) associations within the molluscan assemblage. We also evaluated the level of variation in activity and spatial patterns between sites located a few kilometers apart and compared them to among-species variability. Considering the ample diet overlap among the 4 species, and potential patchiness in the distribution of some species at micro-scales, we hypothesized that, if interspecific interactions are important: (1) species should exhibit different patterns of diel foraging activity; (2) those that do overlap in activity rhythms should exhibit negative spatial associations while foraging and resting, unless they use different resting microhabitats (e.g. flat surfaces versus crevices); and (3) there should be no spatial associations between gregarious and non-aggregated species during resting, but they could exhibit negative (or positive) associations while foraging. 


\section{MATERIALS AND METHODS}

Grazer assemblage and study sites. The study was conducted at 2 sites located in central Chile, Pelancura $\left(33^{\circ} 33^{\prime} \mathrm{S}, 71^{\circ} 37^{\prime} \mathrm{W}\right)$ and Las Cruces $\left(32^{\circ} 43^{\prime} \mathrm{S}\right.$, $71^{\circ} 38^{\prime} \mathrm{W}$ ), which are separated by $\sim 5 \mathrm{~km}$. Pelancura is an extensive rocky shore directly exposed to the prevailing southwestern swell. Las Cruces, where most observations were conducted, is located $\sim 500 \mathrm{~m}$ south of the marine reserve of the Estación Costera de Investigaciones Marinas (ECIM). This stretch of coastline faces toward the south-southeast whereas Pelancura faces west, and so the latter receives more direct breaking waves than Las Cruces. The sites show a similar intertidal species composition, which conforms well to the general pattern reported for other sites in central Chile (see Santelices et al. 1986, Fernández et al. 2000, Broitman et al. 2001). The most common molluscan herbivores at the mid intertidal levels are chitons ( 2 species; Otaíza \& Santelices 1985, Aguilera \& Navarrete 2007), scurrinid limpets ( 2-4 species; see Espoz et al. 2004), fissurellid limpets ( 3-4 species; see Oliva \& Castilla 1986) and a pulmonate limpet species. In this study we concentrated on the 4 most abundant species in terms of total biomass: the chiton Chiton granosus, the pulmonate limpet Siphonaria lessoni, the scurrinid limpet Scurria araucana and the keyhole limpet Fissurella crassa. Additional observations were also conducted on Scurria ceciliana, which, in certain habitats (i.e. mussel beds), can be more abundant than S. araucana. Because F. crassa is commercially exploited, abundance of large adult individuals is generally low at open-access shores compared with in reserves (Oliva \& Castilla 1986). Therefore, we also recorded the behavior of large individuals inside the ECIM marine reserve.

Spatial distribution. To quantify grazer density, we counted all individuals in fifty $30 \times 30 \mathrm{~cm}$ quadrats, haphazardly positioned along $15 \mathrm{~m}$ transects at midintertidal levels at each study site in October and November 2007, and again in April 2008 at both study sites.

To determine whether individuals were randomly distributed (i.e. spatially independent), aggregated or more uniformly distributed over the platforms, we followed 2 approaches. The first approach was density based. We positioned contiguous quadrats of 3 different sizes $(15 \times 15 \mathrm{~cm}, 30 \times 30 \mathrm{~cm}$ and $50 \times 50 \mathrm{~cm})$ along $15 \mathrm{~m}$ transects parallel to the shoreline in the mid intertidal zone of Las Cruces and counted the number of individuals of all target species in each quadrat. These preliminary surveys gave us information about the quadrat size ('grain') that was most appropriate to describe distributional patterns of the focal species through autocorrelation analyses (e.g. Fortin \& Dale
2005). Briefly, when autocorrelation using the first distance class is not significant (random distribution of grazers in space) or is negative, it is considered an indication that the sampling unit size is larger than the spatial pattern, or that the quadrat size scale includes more than one process (Fortin 1999). Thus, $50 \times 50 \mathrm{~cm}$ quadrats were considered uninformative for all focal species (results not shown). Quadrats $15 \times 15 \mathrm{~cm}$ in size were informative only for Scurria ceciliana, whereas 30 $\times 30 \mathrm{~cm}$ quadrats were appropriate for all focal species (see 'Results'). Hence, we conducted surveys using 30 $\times 30 \mathrm{~cm}$ quadrats during daytime low tide and the subsequent night-time low tide on the same rocky platforms (45 quadrats for each phase). In addition, the percentage of rock encompassed by crevices was measured using a $30 \times 30 \mathrm{~cm}$ quadrat with 81 intersection points. A similar procedure was conducted at Pelancura, but for simplicity we present correlograms for Las Cruces only.

The second approach was based on linear interindividual (nearest neighbor, NN) distances (see Clark \& Evans 1954, Pielou 1961). Previous studies have used this sampling procedure to describe spatial patterns and interspecific associations in mobile grazers (see Branch 1976, Underwood 1976, Levings \& Franks 1982). We delimited 4 adjacent $3 \times 3$ m areas at Pelancura and Las Cruces and then randomly sampled individuals of each species, measuring the linear distance (cm) to the closest conspecific during the day in one area and at night in the other area (number of individuals sampled for each area: 25 Fissurella crassa, 150 Siphonaria lessoni, 90 Chiton granosus and 50 Scurria araucana). In the third and fourth $3 \times 3 \mathrm{~m}$ areas we recorded NN distances to heterospecific individuals during the day and at night, respectively (individuals sampled for each area: 23 F. crassa, 200 S. lessoni, 80 C. granosus and 52 S. araucana). In this manner, we obtained independent data sets for intra- and interspecific NN distances during the day and at night. We measured distances when individuals were motionless, either resting or feeding. Thus, the distribution of individuals could change over time but, through random sampling throughout a tidal cycle, we could compare foraging and resting phases.

Activity rhythms. Field: Observations to characterize activity rhythms were conducted at Las Cruces in December 2007 and April to October 2008, and in November and December 2007 and April to June 2008 at Pelancura. A total of 50 adults (100 for Siphonaria lessoni) of each species (mean length $\pm \mathrm{SD}$ : Chiton granosus $=5.5 \pm 0.37 \mathrm{~cm}$; Fissurella crassa $=7.1 \pm 3.9 \mathrm{~cm} ;$ Scurria araucana $=2.6 \pm 1.2 \mathrm{~cm} ;$ S. lessoni $=0.97 \pm$ $0.07 \mathrm{~cm}$ ) were marked with bee tags carefully glued directly to the shell (fifth-plate of chitons), without dislodging the individuals from the substratum and caus- 
ing as little disturbance as possible. Then, we monitored the number of active (foraging) and inactive (resting) individuals at 15 min intervals for $\geq 3 \mathrm{~h}$ during 2 to 3 consecutive days/nights.

Laboratory: Because of the difficulty of observing individuals during high tides on wave-exposed platforms, we also quantified the activity of individuals under laboratory conditions. Approximately 10 to 12 (20 for Siphonaria lessoni) individuals of each species were collected during low tides at Las Cruces and placed in separate 'arenas' at the ECIM laboratory. Experimental arenas consisted of $40 \times 40 \mathrm{~cm}$ concrete blocks with a $20 \times 8 \times 4 \mathrm{~cm}$ crevice carved in the center to provide shelter. The arenas were surrounded with a $10 \mathrm{~cm}$ high fence made of coarse plastic mesh to prevent animals from abandoning the blocks, and the units were randomly placed inside separate aquaria with running seawater and air. High and low tides were simulated by completely immersing and completely exposing arenas to air following the natural tidal cycle observed at the time of experiments. Food was provided ad libitum in the form of a mix of Ulva spp. and fronds of the corticated alga Mazzaella laminarioides, which were directly glued to acrylic plates and affixed to concrete blocks. Microalgae were allowed to settle and grow on the block, thus providing an additional source of food. The number of individuals inside the experimental arenas was chosen according to the natural density of individuals observed in the field when animals are resting: 6 Chiton granosus, 10 S. lessoni, 2 Scurria araucana and 2 Fissurella crassa. There were 2 replicates per species. We recorded the number of active individuals at $3 \mathrm{~h}$ intervals throughout the day and night for 7 consecutive days.

Displacement and homing behavior. To describe the spatial extension of displacement of individuals while foraging and to quantify the degree of homing behavior (resting place fidelity), we used 2 different but complementary methodologies. First, we recorded changes in the position of marked individuals (the same individuals as those used for assessing activity rhythms in the field) using triangulation in an $x-y$ coordinate system (Focardi \& Chelazzi 1990). To this end, we fixed a $5 \mathrm{~m}$ measuring tape to a gently sloping $13 \mathrm{~m}$ platform located at Las Cruces and registered the position of individuals along this $x$-axis. With another measuring tape, extended perpendicular to the first axis, we recorded the position of the individuals along the $y$-axis. The position of individuals was recorded every $12 \mathrm{~h}$, according to the resting-foraging phases observed for most species, during diurnal and nocturnal low tides for 7 consecutive days. Displacement was calculated as the minimum Euclidean distance (diagonal) between consecutive positions. The activity phase for nocturnal foragers (see 'Results') was defined as the change in position between the diurnal initial location $\left(D_{j}\right)$, the nocturnal location $\left(N_{j}\right)$, and the following diurnal location $\left(D_{j+1}\right)$ (Focardi \& Chelazzi 1990). For diurnal foragers, the initial location was nocturnal $\left(N_{j}\right)$.

Second, to obtain more precise estimates of displacement and homing behavior, we recorded the distance (paths) traveled by marked individuals (the same individuals as those used for assessing activity rhythms in the field) at intervals of 15 to $30 \mathrm{~min}$ for 3 to $5 \mathrm{~h}$ during the low tide, over 5 to 7 consecutive days. The distance traveled was measured from the site where individuals were observed inactive at the first low tide (resting site), which was marked with epoxy and considered as a $\sim 5 \mathrm{~cm}$ diameter around the individual, in the case of solitary individuals, and as an oval ca. 5 to $10 \mathrm{~cm}$ in diameter around a clump of individuals in the case of aggregations. Observations were conducted during 2 separate weeks in April 2008 for Scurria araucana and Siphonaria lessoni (Las Cruces), and during 2 separate weeks in April 2009 for Chiton granosus and S. lessoni (Las Cruces). For Fissurella crassa, observations were conducted during 1 wk in October, November and December 2008. Because most F. crassa marked at Las Cruces were lost (probably to human gathering), we conducted observations on this species inside the ECIM marine reserve. Although studies on other systems have shown seasonal variation in behavioral patterns (e.g. Gray \& Hodgson 1997), we did not detect differences in spatial patterns, activity rhythms or displacement distances among surveys or in comparison with previous studies by Serra et al. (2001) on F. crassa inside the ECIM marine reserve or by Aguilera \& Navarrete (2007) on C. granosus on other exposed platforms. Therefore, data from different surveys were pooled for analyses (see below). With this information we computed an index of relative homing error (RHE) (Focardi \& Chelazzi 1990) as: RHE $=\mathrm{HE} / \mathrm{L}$, where HE corresponds to homing error (i.e. $D_{j}$ minus $D_{j+1}$ for nocturnal foragers, and $N_{j}$ minus $N_{j+1}$ for diurnal foragers), and $L=$ length of foraging excursion. Animals with RHE $=0$ exhibit a strong homing performance and RHE $=1$ a complete dispersive pattern.

Data analysis. The spatial structure of grazer density was analyzed using Moran's I spatial correlograms (Sokal \& Oden 1978, Fortin \& Dale 2005) separately for each species and day/night surveys. As recommended (Rossi et al. 1992, Erlandsson et al. 2005), we only interpreted distances less than half the transect length because correlograms do not represent significant information at lags longer than this scale because of the decrease in degrees of freedom (few distance pairs) (Legendre \& Fortin 1989). To determine whether autocorrelation coefficients were significant at $\alpha=$ 0.05, we used bootstrapping (Manly 1997), which com- 
pares the autocorrelation statistic (Moran's I) calculated for the observed data with the distribution of values obtained by randomly sampling the data set and recalculating the coefficients 1000 times. Before examining individual significance values in the correlogram, we performed a global test by checking whether the correlogram contained at least one significant correlation after probabilities were adjusted using a Bonferroni correction for multiple tests $(\alpha=0.05 /$ number of distance classes). Before analyses, data were normalized to zero mean and unit variance to remove outliers. To evaluate the degree of positive/negative spatial association among grazer species and between grazers and crevices (percent cover at the $30 \times 30 \mathrm{~cm}$ scale), we used simple Pearson linear correlations (r).

In general, NN distances are difficult to analyze by conventional statistics because of non-independence due to the existence of reflexive NN pairs (i.e. when 2 points are mutual nearest neighbors; see Cox 1981). Moreover, changes in mean or median distance between conditions (day/night) or species can occur because of changes in distribution or density, which makes it difficult to interpret results of null hypothesis tests. Therefore, we first visually examined the distribution of conspecific NN distances between the resting and foraging phases, among species and between the 2 sites. We determined the general form of the spatial distribution by calculating the mean $\mathrm{NN}$ distance $(d A$, where $d$ is the distance in $\mathrm{cm}$ from a given individual to its nearest neighbor and $A$ is the total survey area) and compared it with the expected $(E) \mathrm{NN}$ distance based on a random distribution model: $d E=1 / 2 \sqrt{ } \rho$ where $\rho$ is the density of individuals within the survey area (Clark $\&$ Evans 1954). Thus, the $R$-statistic $=d A / d E$ provides a measure of the level of aggregation ( $R$ close to 0$)$ or random ( $R$ close to 1$)$ or uniform ( $R$ close to 2.15 for perfect overdispersion) distribution (Clark \& Evans 1954, see also Fortin \& Dale 2005). Because no large differences were observed between sites (see 'Results'), for the sake of space we present NN distribution figures for Las Cruces only.

Interspecific NN distances are also complex to analyze because the expected distance between 2 species, in the absence of any interaction, depends on the distributions of the 2 intraspecific distances (Dixon 1994). Therefore, we used 2 complementary approaches. First, we visually examined NN distributions and changes in the median and mean intra- versus interspecific distances during resting and foraging. Second, we estimated the degree of segregation between all possible pairs of species during resting and foraging following the general method of NN abundance proposed by Pielou (1961). The method is based on the relative abundance of conspecific and heterospecific neighbors within a certain distance from focal individ- uals. Thus, 2 species are segregated if the ratio of conspecific to heterospecific nearest neighbors is greater than expected by chance and attracted when the ratio is less than expected. The $S_{i j}$ index proposed by Dixon (1994), based on the observed frequency of conspecific neighbors relative to the expected frequency of each species was calculated as: $S_{i j}=\log \left(n_{i j} / n_{i j}\right) /\left(N_{i}-1\right) / N_{j \prime}$ where $n_{i i}$ is the number of grazer species $i$ with conspecific neighbors $i$, and $n_{i j}$ is the number of grazer species $i$ with heterospecific neighbors $j_{1} N_{i}$ and $N_{j}$ are the total number of grazers considered of species $i$ and $j_{\text {, }}$ respectively. Thus, $S_{i j}<0$ indicates interspecific spatial segregation, $S_{i j}>0$ an attraction and $S_{i j}=0$ a random pattern. A $2 \mathrm{df}$ significance test proposed by Dixon (1994), which takes into account reflexive points, was used to test whether the observed segregation index was different from randomly labeling species positions.

To determine differences in grazer activity in the laboratory trials between immersed individuals (high tide) and those exposed to air (low tide), we conducted a 2-way ANOVA on log +1 transformed proportions of active animals, considering tide condition and grazer species as fixed factors. Log transformation was necessary to achieve homoscedasticity. For this analysis, we only considered those records in which animals were observed active during the daily phase of activity.

Position of individuals between successive field surveys in the $x-y$ coordinate system allowed us to estimate orientation of grazer displacements while foraging. Thus, circular statistics (i.e. mean, variance and concentration; Batschelet 1981) were computed with Oriana version 3.0 (Kovach Computing). Mean values are presented $\pm \mathrm{SE}$.

\section{RESULTS}

\section{Spatial distribution}

The grazers Chiton granosus, Siphonaria lessoni, Scurria araucana and Scurria ceciliana were the most abundant species in terms of number of individuals at mid intertidal levels at the 2 study sites (Fig. 1), whereas the larger keyhole limpet Fissurella crassa was found at much lower densities. Small-bodied species of chitons, snails and limpets, pooled together as 'other grazers' (Austrolittorina araucana, Nodilittorina peruviana, Chiton cumingsi, C. barnesii and Onchidiella sp.) accounted for 48.2 and $49.6 \%$ of overall molluscan grazer density at Las Cruces and Pelancura, respectively.

Contiguous quadrat sampling revealed different spatial patterns among species and, in some cases, marked diel variability within species. Only small differences in spatial distribution patterns were observed 


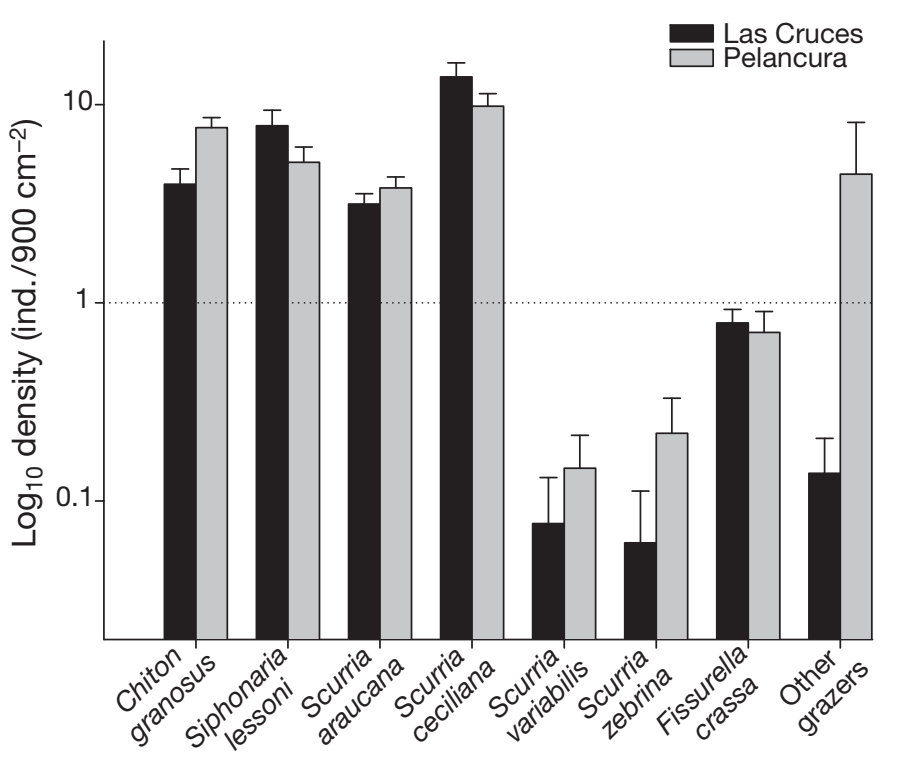

Fig. 1. Benthic grazers (means $+\mathrm{SE}$ ) measured with $30 \times 30$ $\mathrm{cm}$ contiguous quadrats in the mid-intertidal zone of Pelancura and Las Cruces. 'Other grazers' is the pooled number of small or rare mollusk species at the mid-intertidal level (Austrolittorina araucana, Nodilittorina peruviana, Chiton cummingsi, C. barnesii and Onchidella sp.). Dotted line: density of 1 ind. $/ 900 \mathrm{~cm}^{2}$

between sites (Table 1). Here we describe the correlogram-based patterns observed at Las Cruces and note the differences with Pelancura. During daytime at Las Cruces, the distribution of Chiton granosus while resting (see below) was patchy at the scale of the smallest distance class (30 to $60 \mathrm{~cm}$; Fig. 2b) and no other significant structure was observed at other spatial scales (Fig. 2a,b). The distribution of C. granosus during daytime was significantly positively correlated with the distribution of crevices along the same platform at both sites (Table 1). At night, C. granosus individuals spread out slightly, showing a patchy distribution at $\sim 90 \mathrm{~cm}$ as they left the crevices to forage (scale where correlogram crosses from positive to negative autocorrelation values, see Fig. 2b). In this case, a positive correlation was observed at $\sim 300 \mathrm{~cm}$ (Moran's $I=0.298$, $\mathrm{p}=0.0069$ ), which is probably the mean distance between aggregations of feeding individuals. Nonsignificant correlations were observed during this phase between C. granosus and crevice cover at both sites (Table 1). Consequently, a weakly negative, although non-significant, correlation between day and night quadrat densities was observed in this species (Fig. 2a). In the case of Siphonaria lessoni, daytime correlograms, when individuals were actively foraging, showed weak spatial aggregation over scales of $\sim 250 \mathrm{~cm}$ (Fig. 2d). We interpret this as the scale separating aggregations of individuals. A generally similar trend was observed at nighttime, when they were usu-
Table 1. Pearson linear correlations (r) between molluscan grazer densities, and between grazer density (ind./900 $\mathrm{cm}^{2}$ ) and crevice cover $(\%)$ measured in $30 \times 30 \mathrm{~cm}$ quadrats, for day and night low tides at Las Cruces (first line) and Pelancura (second line). Significant correlations $(p<0.05)$ are in bold

\begin{tabular}{|crrrl}
\hline $\begin{array}{c}\text { Siphonaria } \\
\text { lessoni }\end{array}$ & $\begin{array}{c}\text { Scurria } \\
\text { araucana }\end{array}$ & $\begin{array}{c}\text { Fissurella } \\
\text { crassa }\end{array}$ & Crevice & \\
\hline Day & & & & \\
0.075 & -0.104 & $\mathbf{0 . 4 9 5}$ & $\mathbf{0 . 5 6 0}$ & Chiton \\
-0.090 & 0.031 & $\mathbf{0 . 3 2 7}$ & $\mathbf{0 . 3 2 6}$ & granosus \\
& $\mathbf{0 . 4 5 4}$ & -0.179 & $\mathbf{0 . 3 9 5}$ & S. lessoni \\
& $\mathbf{0 . 2 6 1}$ & -0.110 & $\mathbf{- 0 . 1 0 7}$ & \\
& & 0.177 & -0.204 & S. araucana \\
& & -0.055 & -0.151 & \\
& & & 0.113 & F. crassa \\
Night & & & 0.216 & \\
-0.269 & 0.136 & $\mathbf{0 . 3 4 8}$ & -0.028 & C. granosus \\
-0.038 & 0.031 & $\mathbf{0 . 2 2 0}$ & 0.217 & \\
& 0.102 & $\mathbf{- 0 . 3 7 2}$ & 0.157 & S. lessoni \\
& -0.001 & -0.108 & 0.012 & \\
& & 0.188 & 0.274 & S. araucana \\
& & $\mathbf{0 . 2 2 7}$ & 0.226 & \\
& & & -0.162 & F. crassa \\
& & & -0.066 & \\
\hline
\end{tabular}

ally found resting inside crevices, but the scale of aggregations was reduced to $\sim 30 \mathrm{~cm}$ (Fig. 2d). Significant positive correlations between day and night quadrat densities also suggest that individuals have similar spatial distributions while resting and foraging (see Fig. 2c). Furthermore, this pulmonate limpet showed a significant positive correlation with crevice cover during daytime at Las Cruces, but this correlation was negative at Pelancura during this phase. Correlations in this species were non-significant but positive during nighttime at the 2 sites (Table 1). In the case of Scurria araucana, the correlogram for daytime observations, when individuals were largely resting, showed a spatial structure similar to that of S. lessoni, with aggregations of $\sim 250 \mathrm{~cm}$. At nighttime, the spatial distribution appeared to be random, without indication of aggregation at the smallest $(30 \mathrm{~cm})$ spatial scales (Fig. 2e,f), and there was no significant association with crevice cover at either site (Table 1). The most contrasting spatial patterns were observed in Fissurella crassa, which showed no significant structure at any spatial scale, either during daytime or nighttime observations (Fig. 2h).

Spatial interspecific associations among grazers were consistent between study sites for most species pairs (Table 1). The density of Chiton granosus and Fissurella crassa showed a strong positive correlation both during daytime, when they were resting in crevices, and during nighttime, when they were forag- 


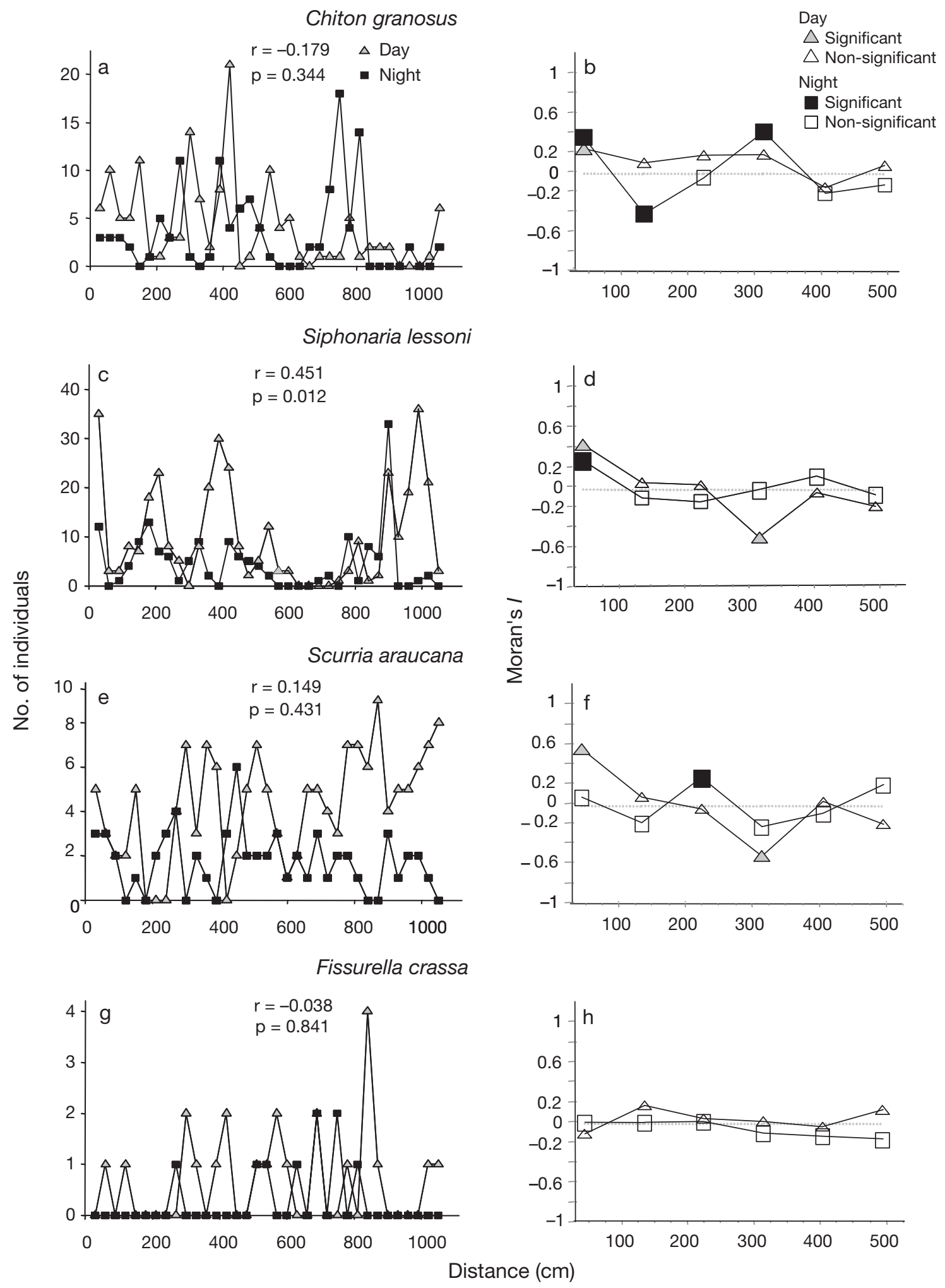

Fig. 2. Density of species along the wave exposed platforms (a,c,e,g) and corresponding Moran's $I$ spatial correlograms (b,d,f,h) of the 4 molluscan grazer species: Chiton granosus, Siphonaria lessoni, Scurria araucana and Fissurella crassa. Density was measured with $30 \times 30 \mathrm{~cm}$ quadrats in the mid-intertidal zone at Las Cruces. Pearson's correlation coefficients and significance levels between day and night sampling are also presented. Solid symbols in correlograms indicate significant correlations $(\alpha=0.05)$ after random permutation tests (1000 permutations) and Bonferroni correction. See text for details 
ing (Table 1). Similarly, the density of Scurria araucana was strongly and positively associated with the density of Siphonaria lessoni during daytime, but the relationship disappeared during nighttime when $S$. lessoni was resting (Table 1). In contrast, F. crassa was negatively, but weakly, associated with $S$. lessoni during daytime and particularly at nighttime at the 2 study sites. Correlations between the other species fluctuated in direction between daytime and nighttime observations. Non-significant correlations were observed between $S$. lessoni and C. granosus and between $S$. lessoni and $S$. araucana at the 2 study sites (Table 1).

In general, Euclidian NN distances among conspecifics changed between the foraging and resting phases for most species (Figs. 3-6, panels $\mathrm{d}$ and $\mathrm{h}$ ). In the case of Chiton granosus and Siphonaria lessoni, we observed a high frequency of individuals in contact with each other (distance zero, median $\mathrm{NN}=0$ ) during the resting phase (87.9 and $57.1 \%$ for daytime and nighttime observations, respectively). Consequently, the $R$-statistic (Clark \& Evans 1954) indicated a significantly aggregated distribution for both species, although it was slightly stronger in C. granosus than in S. lessoni (Figs. $3 \& 4$, compare panels $\mathrm{d}$ and $\mathrm{h}$ ). When foraging at night, C. granosus spread out from the aggregations, increasing the median distance between individuals to $3.54 \mathrm{~cm}$, which was also reflected in the $R$-statistic, but they still conformed to an aggregated distribution (Fig. 3h). In contrast, S. lessoni did not substantially change NN distances when foraging and the $R$-statistic showed virtually no change (see Fig. 4h). Thus, the NN distances for the chiton and pulmonate limpet are in general agreement with the quadrat-based analyses, suggesting the existence of tight aggregations in these species at the scale of quadrat size (ca. $30 \mathrm{~cm}$ ) and significant spatial structures again at around $300 \mathrm{~cm}$, probably reflecting patchiness of aggregations. In the case of Scurria araucana, few individuals were in contact with each other ( $<10 \%$ zero distances $)$, the median distance was $\sim 5.4 \mathrm{~cm}$ (Fig. $5 \mathrm{~d}$ ) and the $R$-statistic showed values that suggested a nearly random distribution. When foraging, the median distance increased to $7.0 \mathrm{~cm}$, but the $R$-statistic still conformed to a nearly random distribution (Fig. 5h). The positive correlation (aggregated pattern) at the scale of quadrat size and the spatial structure at scales of $\sim 250 \mathrm{~cm}$ shown by the quadrat-based correlogram (see Fig. 2f) were not

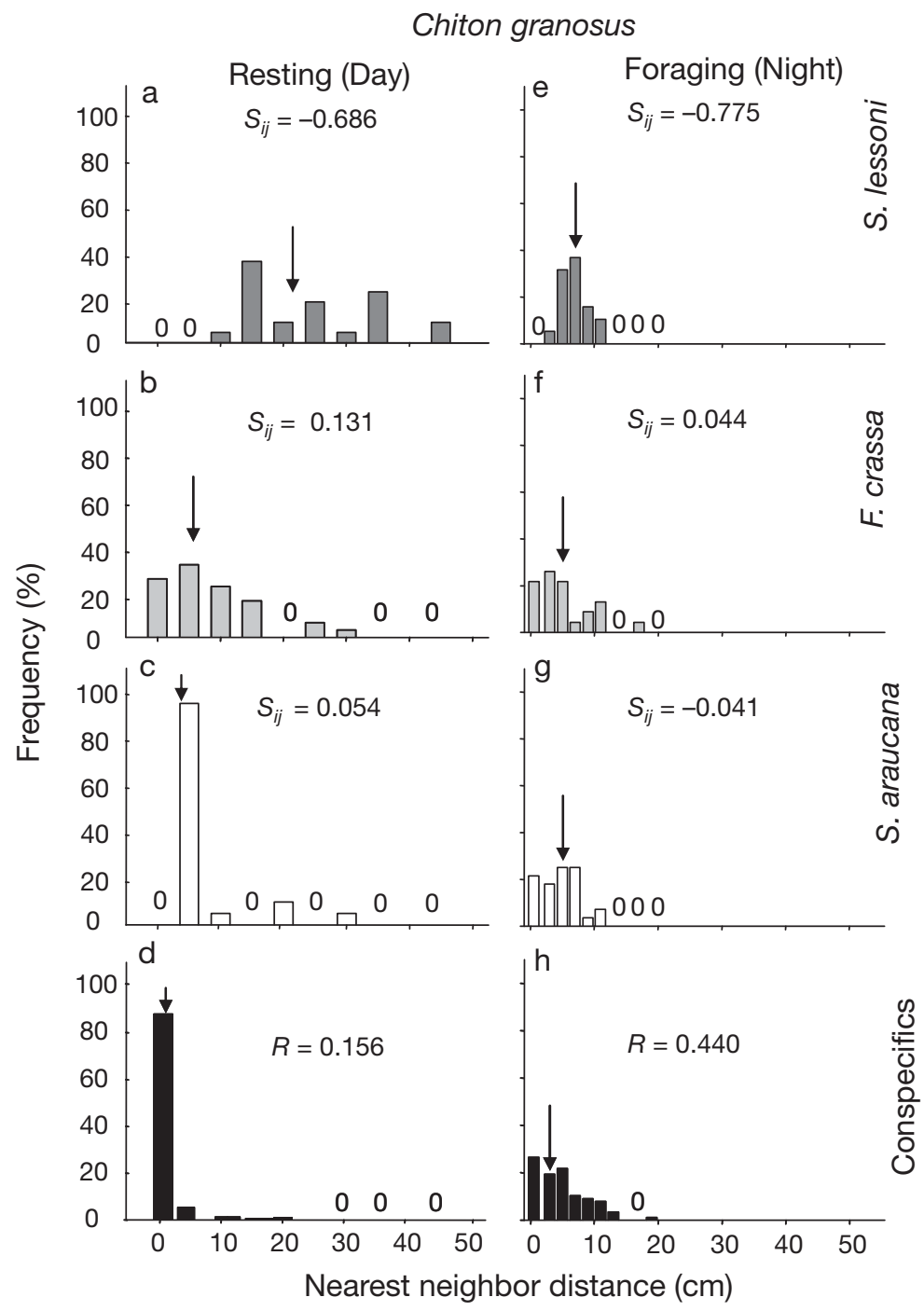

Fig. 3. Frequency distribution of nearest neighbor (NN) distances $(\mathrm{cm})$ for the chiton Chiton granosus at mid-intertidal levels at Las Cruces during resting $(\mathrm{a}-\mathrm{d})$ and foraging $(\mathrm{e}-\mathrm{h})$. Distances to individuals of other grazer species and to conspecific individuals are shown in different panels. Arrows indicate the median NN distance. The segregation index $\left(S_{i j ;}\right.$ see Dixon 1994) is presented for all heterospecific comparisons, where negative values indicate segregation and positive values indicate attraction. The $R$-statistic (Clarke \& Evans 1954) is presented for conspecific NN distances, where values close to 0 indicate aggregated pattern whereas those close to 1 indicate a random pattern of distribution. Full species names in Fig. 1

apparent when measuring individual distances. The frequency of individuals in contact with each other was also low $(16.6 \%)$ in Fissurella crassa. Individuals of this species tend to be at a median distance of $5.5 \mathrm{~cm}$ apart during resting (mean $=12.6 \pm 2.24 \mathrm{~cm}$ ) and the $R$-statistic showed a nearly random distribution (Fig. 6d). However, while foraging, the inter-individual distance increased to a median of $28.0 \mathrm{~cm}$ (mean = $30.7 \pm 2.87 \mathrm{~cm}$ ) and the $R$-statistic showed a more uniform distribution (Fig. 6h). 




Fig. 4. Frequency distribution of nearest neighbor distances $(\mathrm{cm})$ for the pulmonate limpet Siphonaria lessoni at mid-intertidal levels at Las Cruces during resting $(\mathrm{a}-\mathrm{d})$ and foraging $(\mathrm{e}-\mathrm{h})$. See Fig. 3 legend for details. Full species names in Fig. 1

In general, the spatial distribution of grazers between the study sites tended to be consistent for each species (Table 2), with generally slight variations in the $R$-statistic, probably attributed to slight differences in density (see Fig. 1) and micro-scale habitat conditions between these sites. The species Chiton granosus and Siphonaria lessoni had aggregated patterns of distribution and similar diel differences at Las Cruces and Pelancura whereas Scurria araucana conformed to a nearly random distribution and Fissurella crassa to a more uniform distribution at both sites (Table 2). The largest difference between sites was observed in S. lessoni, which exhibited a stronger nighttime aggregation at Pelancura than at Las Cruces, but the general diel difference was similar to that observed in Las Cruces (Table 2).

The values of the $S_{i j}$ segregation index (Dixon 1994) were in general agreement with observed differences in median heterospecific NN distances. In the case of Chiton granosus during the resting phase (Fig. 3, left panels), the median distances to Scurria araucana and Fissurella crassa (Fig. 3b,c) were only slightly larger (median $=3.5$ and $5.0 \mathrm{~cm}$, respectively) than distances to conspecifics (median $=0 \mathrm{~cm}$, see Fig 3b-d), whereas distances to Siphonaria lessoni (Fig. 3a) were over $25.0 \mathrm{~cm}$ larger than those between conspecifics (compare Fig. 3a and 3d). Similarly, $S_{i j}$ values showed a high level of segregation between resting $C$. granosus and $S$. lessoni and a slight attraction of $C$. granosus to $S$. araucana and particularly $F$. crassa. When C. granosus individuals were foraging (Fig. 3, right panels) and tended to be slightly more dispersed (median $=3.15 \mathrm{~cm}$; Fig. 3h), interspecific distances to $S$. araucana and $F$. crassa were further reduced (median = 4.2 and $4.4 \mathrm{~cm}$, respectively). Distances to S. lessoni in this activity phase were also shorter than when individuals were resting (compare Fig. 3e and 3h), but remained larger than distances to other species (Fig. 3f,g). Similarly, the segregation index showed larger segregation from $S$. lessoni and attraction to $F$. crassa. Resting S. lessoni were observed in close proximity to $S$. araucana and F. crassa, although they were never in direct contact with the latter (Fig. $4 \mathrm{~b}, \mathrm{c}$ ). The $S_{i j}$ index showed high segregation from $F$. crassa and low levels of segregation from $S$. araucana (Fig. 4b,c), but because of low sample size $(n=40)$, the estimated index for $F$. crassa must be interpreted with caution. In agreement with observations on chitons as the focal species, the distances between $S$. lessoni and C. granosus were much larger than to conspecifics (Fig. 4 a) and the $S_{i j}$ index suggests strong segregation between these species. Interestingly, because active (foraging) S. lessoni showed an aggregated distribution, interspecific distances to foraging $F$. crassa increased slightly and the $S_{i j}$ index suggested strong segregation during this activity phase (Fig. 4). In the case of the limpet $S$. araucana as a focal species, we observed only slight changes in median interspecific distances during resting or foraging (Fig. 5). The $S_{i j}$ index suggested a pattern of segregation from C. granosus and F. crassa during resting and foraging, respectively (see Fig. 5a,c,e,g), and from $S$. lessoni only when resting (Fig. 5b). F. crassa tended to stay in close proximity to C. granosus at resting, even closer than the 




Fig. 5. Frequency distribution of nearest neighbor distances $(\mathrm{cm})$ for the scurrinid limpet Scurria araucana at mid-intertidal levels at Las Cruces during resting $(\mathrm{a}-\mathrm{d})$ and foraging $(\mathrm{e}-\mathrm{h})$. See Fig. 3 legend for details. Full species names in Fig. 1

median distance to conspecifics (median $=0.5 \mathrm{~cm}$ to $C$. granosus versus $5.5 \mathrm{~cm}$ to conspecifics; Fig. 6). In accordance, the segregation index showed attraction between these species during this activity phase (Fig. 6a). At night, when F. crassa were foraging, distances to conspecifics increased (Fig. 6h) and distances to heterospecifics decreased considerably, rendering a pattern of attraction with all other grazers (Fig. 6e-g).

\section{Activity rhythms}

Daily activity of the 4 focal species recorded in the field were remarkably similar between sites in terms of diel variation in activity as well as in the percentages of individuals found active during day or night low tides (Fig. 7). Averaging across surveys and sites, neap-spring tidal cycle had no effect on grazer activity, except for a slight increase in the diurnal activity of Scurria araucana during neap tides compared with spring tides (Fig. 8a,b). Chiton granosus and Fissurella crassa showed well-defined cycles of nocturnal activity and resting during the day whereas Siphonaria lessoni exhibited daytime activity (Fig. 8a,b). In general, chitons were active between 20:00 and 04:30 $\mathrm{h}$, both during spring and neap tides. F. crassa showed peak activity after sunset, around 19:00 $\mathrm{h}$ and between 03:00 and 05:00 $\mathrm{h}$ in the morning, and $S$. lessoni were active at dusk, around 05:30 h, as well as during mid-morning and afternoon low tides. Although we could not make detailed high tide observations, movement and foraging of $S$. lessoni clearly decreased with incoming tides. $S$. araucana showed the most variable activity rhythm: this species exhibited both day and nighttime activity, particularly during neap tide (Fig. 8a).

Laboratory results showed similar day/ night activity patterns to those observed in the field (Fig. 8c) and only slight differences between low (emersion) and high (immersion) tides (Fig. 8d). The largest differences between field and laboratory observations were observed in Scurria araucana and Siphonaria lessoni. The former was slightly more active during daytime than nighttime hours in the laboratory than in the field and slightly more active when immersed than when exposed to air (Fig. 8c,d). In the case of $S$. lessoni, individuals were mostly active during daytime, as observed in the field, but on some occasions activity extended to early nighttime hours ( 20:00 h) in the laboratory (see Fig. 8c). No differences in activity were observed in this species when immersed or exposed to air (Fig. 8d). Consequently, a 2-way ANOVA showed no significant differences between activity in immersion and air exposure for any of the species (Table 3 ).

\section{Displacements and homing behavior}

Through discrete (changes in position between consecutive low tides) and semi-continuous (every $15 \mathrm{~min}$ for $3 \mathrm{~h}$ on 5 consecutive days) observations, we characterized patterns of displacement and distances traveled of each species (Fig. 9). Both types of measure- 


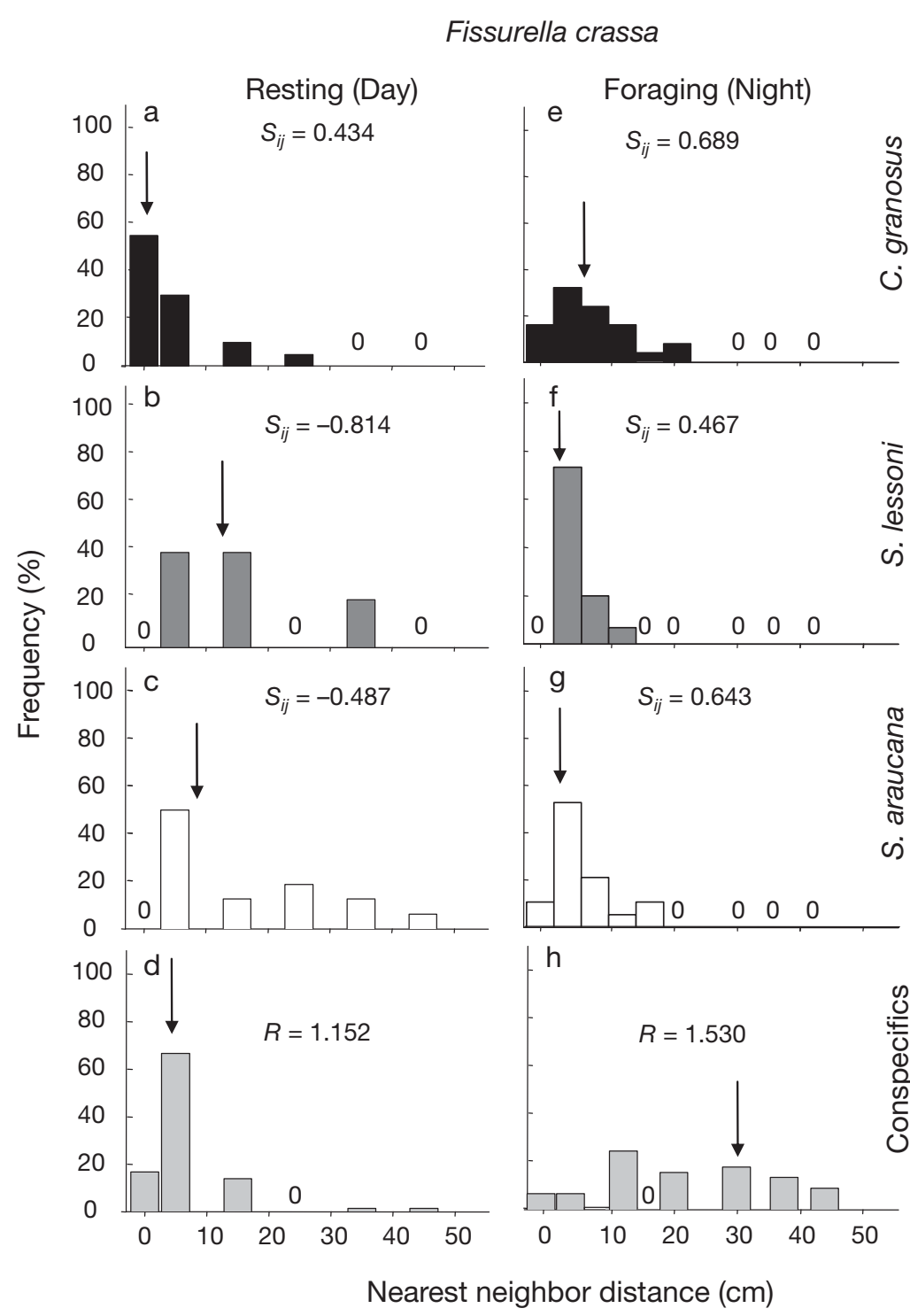

Fig. 6. Frequency distribution of nearest neighbor distances $(\mathrm{cm})$ for the keyhole limpet Fissurella crassa at mid-intertidal levels at Las Cruces during resting $(\mathrm{a}-\mathrm{d})$ and foraging $(\mathrm{e}-\mathrm{h})$. See Fig. 3 legend for details. Full species names in Fig. 1

ments gave similar results. We used the more extensive discrete observations based on the $x-y$ grid to estimate orientation angles, but as this method tended to underestimate the extension of foraging bouts, we used semi-continuous observations to estimate excursion distances and homing behavior. Mean displacement distances were $60.1 \pm 5.2 \mathrm{~cm}$ in Fissurella crassa, $54.2 \pm 5.9 \mathrm{~cm}$ in Chiton granosus, $24.6 \pm 3.7 \mathrm{~cm}$ in Siphonaria lessoni and only $6.5 \pm 3.9 \mathrm{~cm}$, with a maximum displacement of $16 \mathrm{~cm}$, in Scurria araucana (Fig. 9c). In the case of F. crassa and C. granosus, $\sim 8.0 \%$ of individuals moved beyond $100 \mathrm{~cm}$ while foraging (Fig. 9a,d) whereas only $5.3 \%$ of $S$. lessoni individuals reached this distance (Fig. 9b).
During foraging excursions, individuals showed a predominant angle of orientation (Raleigh's $z=11.09,6.48$ and 7.26 for Chiton granosus, Siphonaria lessoni and Scurria araucana, respectively, $\mathrm{p}<0.001)$. The statistic could not be calculated for Fissurella crassa. The $0-180^{\circ}$ axis (insets in i Fig. $9 \mathrm{a}-\mathrm{c}$ ) corresponded to the sea-land axis on the platforms and 0 and $110^{\circ}$ to the main direction of incoming waves. The mean displacement vectors of $C$. granosus, $S$. araucana and $S$. lessoni were $115.6 \pm$ ₹ $11.3^{\circ}, 123.6 \pm 12.9^{\circ}$ and $183.6 \pm 15.2^{\circ}$, respectively, suggesting that the first 2 species oriented foraging toward incoming

(j) waves whereas S. lessoni foraged away from incoming waves (Fig. 9a,b,d insets).

Contrasting patterns of homing behaviors were observed among species. Fissurella crassa exhibited a remarkably tight and persistent homing behavior over the 3 mo of observations (RHE $=0.0$; Fig. 9d). Other species exhibited more moderate homing behavior, with the majority of individuals returning to their homes after foraging excursions (Chiton granosus and $S$. araucana; Fig. 9a,c). In the case of of Siphonaria lessoni, $\sim 48 \%$ of individuals returned to their original position after foraging whereas the rest relocated to different resting sites from day to day (Fig. 9b).

\section{DISCUSSION}

Our results show that the spatial distributions of grazers varied among species, from aggregated for Chiton granosus and Siphonaria lessoni to a much more dispersive pattern for Fissurella crassa and Scurria araucana (Table 4a). In most cases, individuals dispersed slightly from aggregation when foraging, except for $S$. lessoni, which tended to forage in conspecific aggregations. A strong positive association was observed between $C$. granosus and F. crassa during resting (day) and foraging (night) whereas a consistent negative association (segregation) was observed between these nocturnally active species and the diurnally active pulmonate $S$. lessoni (Table $4 \mathrm{~b}$ ). Only slight differences in spatial distribution and activity patterns were observed between sites. Distance of foraging excursions varied widely, from over $60 \mathrm{~cm}$ in F. crassa to less than $7 \mathrm{~cm}$ in $S$. araucana, the most sessile of the 4 species studied. Homing behavior also changed among grazers, from extreme fidelity in 
Table 2. $R$-statistic of aggregation for conspecific nearest neighbour distances recorded at Las Cruces and Pelancura during daytime and nighttime low tides. Values close to 0 indicate an aggregated pattern whereas values close to 1 indicate a random pattern of distribution. Values close to 2.149 (the theoretical maximum) indicate an even and widely spaced distance among individuals

\begin{tabular}{|lcc|}
\hline & Las Cruces & Pelancura \\
\hline Chiton granosus & & \\
Day & 0.173 & 0.013 \\
Night & 0.415 & 0.440 \\
Siphonaria lessoni & & \\
Day & 0.367 & 0.459 \\
Night & 0.274 & 0.032 \\
Scurria araucana & & \\
Day & 0.982 & 1.198 \\
Night & 1.376 & 1.058 \\
Fissurella crassa & 1.280 & 1.660 \\
Day & 1.161 & 1.532 \\
Night & & \\
\hline
\end{tabular}

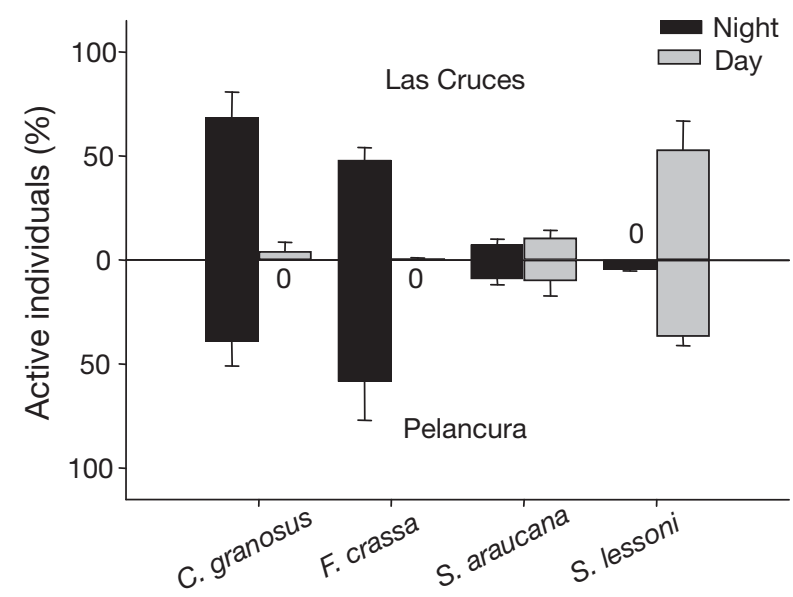

Fig. 7. Activity (\% of individuals, mean $+\mathrm{SE}$ ) of Chiton granosus, Fissurella crassa, Scurria araucana and Siphonaria lessoni, recorded at nighttime and during the daytime at Pelancura and Las Cruces. A total of 50 individuals of each species (100 for $S$. lessoni) were marked with numbered bee tags glued to the shell and activity was recorded during December 2007 and from April 2008 to October 2008 in Las Cruces, and during November and December 2007 and through April 2008 to June 2008 in Pelancura

F. crassa to moderate fidelity in C. granosus and comparatively low fidelity in $S$. lessoni. Overall, our predictions, based on the assumption that interspecific competition was an important process structuring spatial and behavioral patterns in the guild, were only partially held. Thus, taken together, results suggest that interspecific interactions could be important in this guild, but that they involve some and not all species. Here we discuss whether differences in activity patterns of the small-bodied $S$. lessoni might result from interference with the large F. crassa and whether spatial segregation might help reduce interference competition with chiton aggregations for the use of shelters.

\section{Individual spatial distribution and behavioral patterns}

Spatial patterns of distribution have been studied using different methodologies (e.g. Chapman \& Underwood 1992, Underwood \& Chapman 1996, Fortin \& Dale 2005), which place emphasis on different aspects and driving processes of the spatial distribution. We utilized 2 common methodologies, one based on the distribution of density (quadrat-based) and one based on distances among individuals (NN distances). In all species but Scuria araucana, significant autocorrelation values at the smallest scale (i.e. $30 \times 30 \mathrm{~cm}$ quadrats) corresponded well with the highly clumped distribution of distances among individuals detected with the NN method. In the case of $S$. araucana, the quadrat method indicated spatial aggregation within the $30 \mathrm{~cm}$ quadrat scale, but inter-individual distances, measured at much finer scale, did not show an aggregated pattern. Similarly, we observed non-significant autocorrelation values for Fissurella crassa, which is usually indicative that the grain size used $(30 \times 30 \mathrm{~cm})$ was not appropriate to detect the spatial structure in this species, but our results using larger $(50 \times 50)$ or smaller $(15 \times 15 \mathrm{~cm})$ quadrats also failed to show significant spatial structure at day or night. It could also be indicative that densities are too low to correctly interpret the correlograms (Fortin \& Dale 2005), or that the spatial structure is significant only at much larger spatial scales. In this case, as in the case of S. araucana, the NN method might be more informative than the quadrat method. Thus, the 2 methods operate at different scales and thereby capture different processes (see Fortin \& Dale 2005), one (NN) focuses mostly on individual decisions that generate spatial associations, usually over small spatial scales, and the other on processes affecting the spatial distribution of abundance, usually over larger spatial scales. Description of spatial patterns must therefore be explored with diverse methodologies (e.g. Legendre \& Fortin 1989, Legendre et al. 1997, Fortin 1999) to gain insight into the potential processes underlying natural landscapes.

We observed changes in the spatial distribution of most grazers studied between resting and foraging phases (summarized in Table 4a). Chitons commonly aggregate inside crevices at day and disperse slightly when foraging at night. Dispersion during foraging may be the result of quasi-random search for food by individuals, but it may also reduce intraspecific com- 


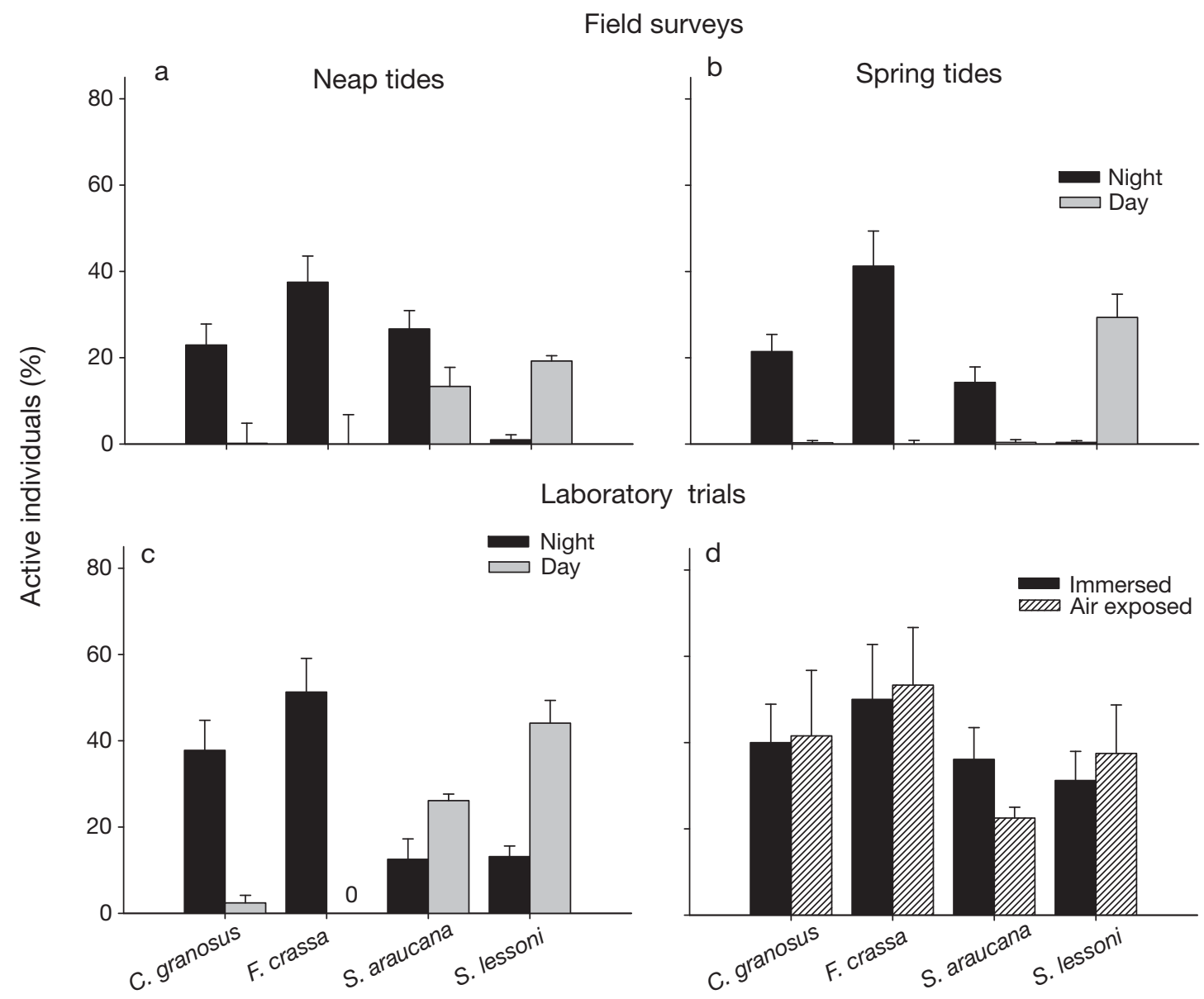

Fig. 8. Activity (\% of individuals, mean $+\mathrm{SE}$ ) of Chiton granosus, Fissurella crassa, Scurria araucana and Siphonaria lessoni, recorded in the field at mid-intertidal levels at Las Cruces and Pelancura (pooled data) during (a) neap and (b) spring tides, and in laboratory trials at ECIM during (c) daytime and nighttime hours and (d) immersed in water and exposed to air

Table 3. 2-way ANOVA comparing activity of grazers in laboratory trials, with condition (immersed in water versus exposed to air) and species (4 species) as fixed factors

\begin{tabular}{|lcccc|}
\hline Source & df & MS & $F$ & $p$ \\
\hline Condition & 1 & 0.012 & 0.31 & 0.590 \\
Species & 3 & 0.046 & 1.15 & 0.385 \\
Condition $\times$ Species & 3 & 0.010 & 0.27 & 0.844 \\
Residual & 8 & 0.322 & & \\
\hline
\end{tabular}

petition among individuals, probably reducing interference during food acquisition (Schoener 1983, Folmer et al. 2010). However, the other gregarious species, the pulmonate limpet Siphonaria lessoni, maintained an aggregated distribution when foraging during daytime hours. We observed tighter aggregations at Las Cruces than at Pelancura in S. lessoni during the active phase, which can be related to differences in density or perhaps to small-scale variation in topography between sites. However, the spatial patterns recorded still conform to an aggregated distribu- tion at both sites. This may also account for the stronger correlation with crevice cover at Las Cruces than Pelancura, which suggests that aggregations tended to be near crevices even when animals were foraging. It is possible that in this species, unlike in chitons, there is a net benefit to foraging in tight groups (e.g. reducing predation risks; Coleman et al. 2004), but this possibility must be further evaluated experimentally. The distribution while foraging may also reflect other individual processes. Indeed, we observed $S$. lessoni individuals commonly engaging in crosscopulation during the activity phase (see also Hodgson 1999).

Like chitons and Siphonaria lessoni, Fissurella crassa utilizes crevices when resting during the day but, contrary to the former species, their spatial distribution is dispersive, which is reinforced by their generally low density (see Oliva \& Castilla 1986). During the foraging phase, the distribution of keyhole limpets tends to be more uniform, which could be related to the large foraging displacements $(60.1 \pm 5.2 \mathrm{~cm})$ and perhaps 


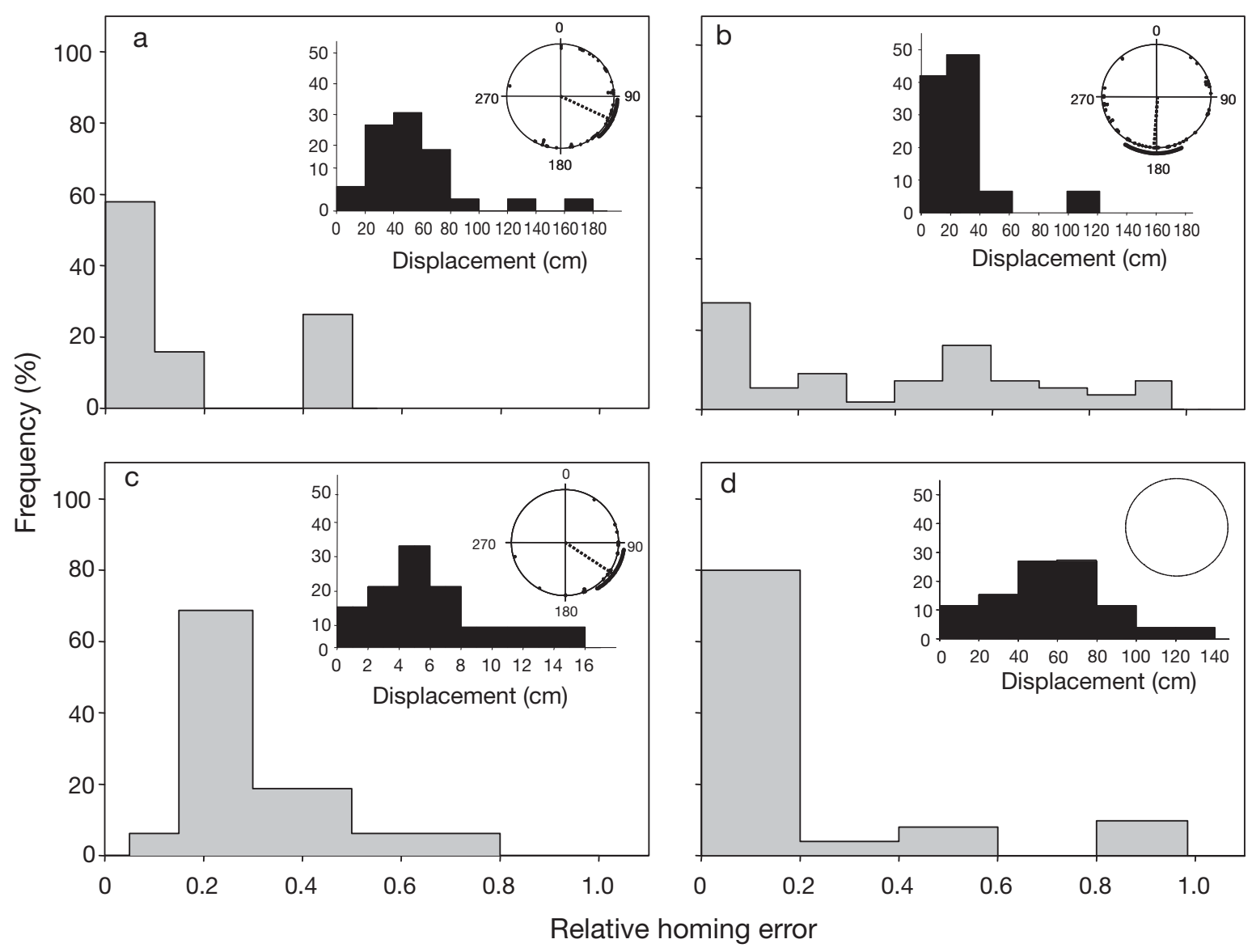

Fig. 9. Frequency distribution of relative homing error (RHE) of (a) Chiton granosus, (b) Siphonaria lessoni and (c) Scurria araucana, recorded through semi-continuous sampling in Las Cruces, and (d) Fissurella crassa, recorded inside the ECIM marine reserve. Values of RHE close to 0 show perfect homing behavior whereas those close to 1.0 show dispersive excursions. For $S$. lessoni, pooled data of 2 separate assessments were considered for this analysis. Insets show the distribution of displacement lengths $(\mathrm{cm})$ and the polar graph shows the distribution of individual orientation (not estimated for $F$. crassa) recorded through discrete positioning of animals during 7 consecutive days on an $x-y$ plane at Las Cruces. Means and SD (dashed lines) of orientation angles are also shown in the polar graphs. Each individual is represented by one data point

to intraspecific interference among foraging individuals. Although the short displacements at foraging (ca. $7.0 \mathrm{~cm}$ ) by Scurria araucana did not permit differentiation of spatial distributions between day and night, the observed interindividual segregation in this species may also be an indication of intraspecific interference, but in this case for spatial territories (see Stimson 1970, Branch 1976, 1981). Most individuals of this limpet species feed on microalgae in the neighborhood of the homing scar, in a manner which resemble 'gardener' limpets on the South African coasts (Branch 1981, McQuaid \& Froneman 1993). However, although most grazers show some level of homing behavior (discussed below) and individual home scars are common in flat platforms for $S$. araucana, we did not observe aggressive encounters in the field in any of the species studied. Thus, further experiments are needed to evaluate the effect of intraspecific interference on the dis- tribution of $F$. crassa and $S$. araucana and determine whether it sets homing strategies in these species.

All species show some level of homing behavior, but individuals of Fissurella crassa had the highest fidelity to resting places (see also Serra et al. 2001). Because F. crassa individuals commonly rest solitarily, they may have individual-specific trail recognition cues (e.g. mucus trails) to ensure the return to the same home (Chelazzi et al. 1988, Davies \& Hawkins 1998). In turn, gregarious grazers Chiton granosus and Siphonaria lessoni might be able to use trails from different individuals to return home after foraging excursions (Chelazzi et al. 1987). This could account for the high variability in estimates of the homing indices for these species. Unfortunately, our semi-discrete information on individual positions does not allow us to examine the use of specific trails by individuals. Differences in mechanisms used to return to fixed homes be- 
Table 4. (a) Intraspecific spatial and activity patterns during daytime (D) and nighttime (N). (b) Interspecific spatial patterns for the grazers during resting (R) and foraging $(\mathrm{F})$ phases. Spatial patterns were estimated according to nearest neighbour distances and quadrat-based methods. +: positive association; -: negative association; 0: non-significant association. Species: Chiton granosus, Siphonaria lessoni, Scurria araucana and Fissurella crassa

\begin{tabular}{|c|c|c|c|c|c|c|}
\hline \multicolumn{7}{|c|}{ a) Intra-specific spatial and activity } \\
\hline \multirow[t]{2}{*}{ Species } & \multicolumn{3}{|c|}{ Spatial pattern } & & \\
\hline & \multicolumn{2}{|c|}{$\mathrm{D}^{1}$} & $\mathrm{~N}$ & \multicolumn{3}{|c|}{ D Activity phase } \\
\hline C. granosus & \multicolumn{2}{|c|}{ Aggregated } & Dispersed & \multicolumn{3}{|r|}{ Foraging } \\
\hline F. crassa & \multicolumn{2}{|c|}{ Dispersed } & Dispersed & & Resting & Foraging \\
\hline S. lessoni & \multicolumn{2}{|c|}{ Aggregated } & Aggregated & & Foraging & Resting \\
\hline S. auracana & \multicolumn{2}{|c|}{ Dispersed } & Dispersed & & $\begin{array}{l}\text { Foraging- } \\
\text { resting }\end{array}$ & $\begin{array}{c}\text { Foraging- } \\
\text { resting }\end{array}$ \\
\hline \multicolumn{7}{|c|}{ b) Interspecific spatial patterns } \\
\hline \multirow[t]{2}{*}{ Species } & \multicolumn{2}{|c|}{ C. granosus } & \multicolumn{2}{|c|}{ F. crassa } & & S. lessoni \\
\hline & $\mathrm{R}$ & $\mathrm{F}$ & $\mathrm{R}$ & $\mathrm{F}$ & & $\mathrm{R} \quad \mathrm{F}$ \\
\hline F. crassa & + & + & & & & \\
\hline S. lessoni & - & - & - & - & & \\
\hline S. auracana & 0 & 0 & 0 & 0 & & + \\
\hline
\end{tabular}

tween solitary and gregarious species deserve further attention.

Marked differences in day and night activity rhythms were observed among species (see Table 3a). Chitons and Fissurella crassa have well-defined nocturnal activity, which contrasts with the diurnal activity of Siphonaria lessoni. In contrast, the limpet Scurria araucana showed activity in both diurnal and nocturnal hours. It has been suggested that nocturnal activity is an adaptive response of intertidal grazers to avoid thermal stress and/or visual (diurnal) predators (Branch \& Cherry 1985, Little 1989, Chelazzi et al. 1987). Diurnal activity can expose intertidal species to high thermal and desiccation stresses at low tides, which occur toward the sun summit (Finke et al. 2007). Resting in moist and shaded crevices could then significantly reduce these stresses (Branch \& Cherry 1985, Williams \& Morritt 1991, Harper \& Williams 2001). If environmental stress is the main driver of nocturnal grazers, then one should expect the diurnal pulmonate limpet S. lessoni to be more tolerant of temperature and desiccation conditions than keyhole limpets and chitons, as has been shown in other pulmonate species (Branch \& Cherry 1985, Marshall \& McQuaid 1991, 1994). Perhaps the tight aggregations observed while foraging are partly a behavioral response to sustain activity under harsh conditions. But these propositions must be further evaluated. It has also been previously hypothesized that interspecific competition for food has selected for diurnal or nocturnal activity in grazers (Little 1989). According to Little (1989), when competition for food is low, nighttime feeding should be common, whereas when competition for food is high, diurnal activity should predominate. This hypothesis assumes that nocturnal activity is the most suitable time to forage because of low desiccation or other stresses and, therefore, inferior competitors (usually those of smaller body size) would be forced to feed during the more stressful daytime hours. Thus, the diurnal activity of $S$. lessoni may be related to historical interspecific competition with the nocturnal grazers C. granosus and F. crassa, but as we hypothesize below and has been suggested before (Carothers \& Jaksic 1984), interference in the use of crevices (shelters against desiccation) or while feeding on individual plants, instead of food exploitation, might be the most relevant mechanism. Unfortunately, our laboratory experiments show that activity rhythms in these species are rather fixed; therefore, it is difficult to directly test the hypothesis of 'competition past' (sensu Connell 1980) on activity patterns. Individuals of the limpet $S$. araucana showed more plastic diel activity. They might be able to partition the time individuals spend foraging during day and night to compensate for seasonal or short-term changes in environmental conditions, such as rock moisture or wave action (Gray \& Hodgson 1997, Ng \& Williams 2006), or in response to predation risks. Although this species does not display active escape responses in the presence of predators (Espoz \& Castilla 2000), future experimental studies could examine whether individuals respond to the presence of predators by changing diel activity rhythms. We have shown that changes in activity patterns in this grazer assemblage were small or nonexistent between sites separated by a few kilometers, but an interesting and unresolved issue is whether these patterns remain the same at regional or biogeographical scales, where environmental and ecological scenarios change more significantly. The question is whether behavioral patterns in this molluscan assemblage are hard-wired responses, largely determined by ancestry (see Lindberg 2007 for patellogastropods), or whether they are dependent on the local environmental condition to which species could rapidly adapt. As we consider below, information on the variation of grazers' behavior between communities separated by hundreds to thousands of kilometers could shed light on these issues.

It is well known that distributional and behavioral strategies of grazers can have important consequences 
on the spatial distribution of food resources (Chapman \& Underwood 1992, Johnson et al. 2008). Distributions of molluscan grazers at the micro scale and homing can greatly account for spatial autocorrelation or patchiness in food distribution (Johnson et al. 2008). Our results on spatial patterns show that gregarious grazers during resting also tend to maintain aggregated patterns during foraging (although more loosely in Chiton granosus), which concentrates grazing activity at 30 to $45 \mathrm{~cm}$ around shelters. Moreover, our results on the orientation of grazers showed that $C$. granosus and Siphonaria lessoni revisited the same algal patches in successive foraging bouts, which could further reinforce a highly patchy distribution of grazing intensity (M. A. Aguilera \& S. A. Navarrete unpubl. data). The sedentary behavior and dispersed distribution of $S$. araucana guarantees a spatially patchy grazing by this limpet, but their real effects on maintaining homing scars must still be experimentally demonstrated. In contrast, grazing impact by F. crassa must be more spatially extended and more uniform over space. Thus, despite their relatively similar food diets (Santelices et al. 1986, Camus et al. 2008), the impacts of these species on the algal assemblage and therefore their functional roles (Schmitz 2008) might still be quite different.

\section{Spatial and temporal interspecific association}

The observed segregated spatial association during resting and foraging between the gregarious species Siphonaria lessoni and Chiton granosus (summarized in Table 4 b) is only partly in line with our predictions. Chitons and $S$. lessoni have different diel foraging activities and also they commonly aggregate in different crevices during resting in the mid to high intertidal zones, which could be a direct consequence of interference through aggressive behavior (not seen) or crowding effects inside crevices as animals leave or enter the shelters, as seen among other gregarious species (Branch 1976). Thus, segregation in activity does not seem sufficient to reduce and completely eliminate spatial segregation (see Carothers \& Jaksic 1984). Differences in body size (chitons are larger than $S$. lessoni) might produce asymmetry in this interaction (i.e. strong differences in the magnitude of effects between the species), but our data cannot resolve this issue. It is interesting that $S$. lessoni tends to forage during the day at a distance $\sim 30 \mathrm{~cm}$ further from its own resting sites, which also accounts for positive spatial association with crevices during this phase, and $\sim 45 \mathrm{~cm}$ from aggregations of resting chitons, which could be related to food shortage in areas adjacent to chiton crevices (Aguilera \& Navarrete 2007) and there- fore the possibility of exploitative competition for food between these species occurring at very small spatial scales. Segregation during both resting and foraging between $S$. lessoni and solitary F. crassa was also apparent. The small body size of $S$. lessoni compared with $F$. crassa might determine strong asymmetry in encounters when acquiring food, or during the brief times when individuals overlap during initiation and termination of foraging. Indeed, a study in southern Chile has suggested the existence of strong interspecific competition between $S$. lessoni and another large keyhole limpet, Fissurella picta (Godoy \& Moreno 1989), and direct interference might be one of the mechanisms. Again, these spatial patterns and observations reinforce the idea that diurnal activity in $S$. lessoni could be an evolutionary response to reduce encounters with larger nocturnal foragers. In this context, it is interesting to note that the same species has been reported as having nocturnal activity in the Atlantic Patagonia, where large grazers and, therefore, potential competitors are virtually absent (see Olivier \& Penchaszadeh 1968, López-Gappa et al. 1996). Further observations over biogeographic scales, together with carefully designed transplant experiments, could shed light into the potential for competition to set patterns of diel activity. We observed positive spatial association between chitons and F. crassa during both resting and foraging (see Table $4 \mathrm{~b}$ ). Contrary to our predictions, these species utilize the same microhabitats during resting (i.e. crevices) and also forage at the same time (see Table 4a). This suggests that competition (e.g. interference) between these species is less intense than among conspecific individuals. Taken together, our results suggest that interference competition driven by shelter use and modulated by differences in body size may determine the spatial and temporal organization of some of the grazers in the guild. This interaction may also translate into changes in the distribution of the algae consumed by these species. Further experiments should thus examine grazer effects under different contexts of interspecific coexistence.

Although detailed manipulative experiments are needed to elucidate whether activity and spatial distributional patterns are modified by competitive interactions, our study provides information regarding the most likely and important type of interactions in this grazer guild, interference competition, and the species that might be most affected. Similarly, results demonstrate that, despite high diet overlap (see Santelices et al. 1986), there are sharp and sometimes conspicuous interspecific differences in spatial distribution, mobility and foraging behavior, which could very likely translate into important differences in the functional roles played by each grazer species in algal assemblages and the entire community. This information 
sheds light on the roles played by individual behavior and competitive interactions in shaping functional structure in the molluscan grazer assemblage (see Branch 1981), both at ecological and evolutionary scales.

Acknowledgements. We greatly appreciate comments by B. Broitman (CEAZA-UCN), M. Thiel and E. Wieters on an earlier version of the manuscript. This paper is in partial fulfillment of the PhD degree of M.A.A. and was made possible thanks to a scholarship by Comisión Nacional de Ciencia y Tecnología (CONICYT). Support from the Andrew Mellon Foundation to M.A.A. is also greatly appreciated. We thank 'ECIMinianos' and 'Chango-LAB' for camaraderie and friendship. Financial support for these studies was provided by Fondecyt Grant no. 1070335 and Fondap Fondecyt 15001-001 to S.A.N.

\section{LITERATURE CITED}

Aguilera M (2005) Cirripedios en la dieta del molusco herbívoro Chiton granosus Frembly (1827) (Mollusca:Placophora) presente en el intermareal rocoso de Iquique, Norte de Chile. Invest Mar 33:109-113

Aguilera A, Navarrete S (2007) Effects of Chiton granosus (Frembly, 1827) and other molluscan grazers on algal succession in wave exposed mid-intertidal rocky shores of central Chile. J Exp Mar Biol Ecol 349:84-98

Batschelet E (1981) Circular statistics in biology. Academic Press, London

Branch GM (1976) Interspecific competition experienced by South African Patella species. J Anim Ecol 45:507-529

Branch GM (1981) The biology of limpets: physical factors, energy flow and ecological interactions. Oceanogr Mar Biol Annu Rev 19:235-380

Branch GM, Cherry MI (1985) Activity rhythms of the pulmonate limpet Siphonaria capensis Q. and G. as an adaptation to osmotic stress, predation and wave action. J Exp Mar Biol Ecol 87:153-168

Broitman BR, Navarrete SA, Smith F, Gaines SD (2001) Geographic variation of southeastern Pacific intertidal communities. Mar Ecol Prog Ser 224:21-34

Camus PA, Daroch K, Opazo FL (2008) Potential for omnivory and apparent intraguild predation in rocky intertidal herbivore assemblages from northern Chile. Mar Ecol Prog Ser 361:35-45

Carothers JH, Jaksic FM (1984) Time as niche difference: the role of interference competition. Oikos 42:403-406

Castilla JC (1981) Perspectivas de investigación en estructura y dinámica de comunidades intermareales rocosas de Chile Central. II. Depredadores de alto nivel trófico. Medio Ambiente 5:190-215

> Chapman MG (2000) Poor design of behavioural experiments gets poor results: examples from intertidal habitats. J Exp Mar Biol Ecol 250:77-95

Chapman M, Underwood A (1992) Foraging behaviour of marine benthic grazers. In: John DM, Hawkins SJ, Price JH (eds) Plant-animal interactions in the marine benthos. Clarendon Press, Oxford, p 289-317

Chelazzi G, Della Santina P, Parpagnoli D (1987) The trail following in the chiton Acanthopleura gemmata: operational and ecological problems. Mar Biol 95:539-545

Chelazzi G, Focardi S, Deneubourg JL (1988) Analysis of movement pattern and orientation mechanism in intertidal chitons and gastropods. In: Chelazzi G, Vannini G (eds) Behavioural adaptation to intertidal life. Plenum Press, New York, NY, p 173-184

Clark PJ, Evans FC (1954) Distance to nearest neighbor as a measure of spatial relationships in populations. Ecology 35:445-453

Coleman RA, Browne M, Theobalds T (2004) Aggregation as a defense: limpet tenacity changes in response to simulated predator attack. Ecology 85:1153-1159

Coleman RA, Underwood AJ, Benedetti-Cecchi L, Aberg P and others (2006) A continental scale evaluation of the role of limpet grazing on rocky shores. Oecologia 147:556-564

Connell JH (1980) Diversity and the coevolution of competitors, or the ghost of competition past. Oikos 35:131-138

- Cox TF (1981) Reflexive nearest neighbours. Biometrics 37:367-369

> Davies MS, Hawkins SJ (1998) Mucus from marine molluscs. Adv Mar Biol 34:1-71

> Dixon P (1994) Testing spatial segregation using a nearest neighbor contingency table. Ecology 75:1940-1948

> Erlandsson J, McQuaid C, Kostylev V (2005) Contrasting spatial heterogeneity of sessile organisms within mussel (Perna perna) beds in relation to topographic variability. J Exp Mar Biol Ecol 314:79-97

Espoz C, Castilla JC (2000) Escape responses of four Chilean intertidal limpets to seastars. Mar Biol 137:887-892

Espoz C, Lindberg DR, Castilla JC, Simison BW (2004) Los patelogastrópodos intermareales de Chile y Perú. Rev Chil Hist Nat 77:257-283

Fernández M, Jaramillo E, Marquet P, Moreno C and others (2000) Diversity, ecology and biogeography of Chilean benthic nearshore ecosystems: an overview and needs for conservation. Rev Chil Hist Nat 73:629-662

Finke GR, Navarrete SA, Bozinovic F (2007) Tidal regimes of temperate coasts and their influences on aerial exposure for intertidal organisms. Mar Ecol Prog Ser 343:57-62

> Fletcher WJ, Underwood AJ (1987) Interspecific competition among subtidal limpets: effect of substratum heterogeneity. Ecology 68:387-400

> Focardi S, Chelazzi G (1990) Ecological determinants of bioeconomics in three intertidal chitons (Acanthopleura spp). J Anim Ecol 59:347-362

Folmer EO, Olff H, Piersma T (2010) How well do food distributions predict spatial distributions of shorebirds with different degrees of self-organization? J Anim Ecol 79:747-756

Fortin MJ (1999) Effects of sampling unit resolution on the estimation of spatial autocorrelation. Ecoscience 6: 636-641

Fortin MJ, Dale M (2005) Spatial analysis: a guide for ecologists. Cambridge University Press, Cambridge

Godoy C, Moreno C (1989) Indirect effects of human exclusion from the rocky intertidal in southern Chile: a case of cross-linkage between herbivores. Oikos 54:101-106

> Gray D, Hodgson AN (1997) Temporal variation in foraging behaviour of Patella granularis (Patellogastropoda) and Siphonaria concinna (Basommatophora) on a South African shore. J Molluscan Stud 63:121-130

- Harper KD, Williams G (2001) Variation in abundance and distribution of the chiton Achantopleura japonica and associated molluscs on a seasonal tropical, rocky shore. J Zool 253:293-300

Hawkins SJ, Hartnoll RG (1983) Grazing of intertidal algae by marine invertebrates. Oceanogr Mar Biol Annu Rev 21: 195-282

Hodgson AN (1999) The biology of siphonariid limpets (Gastropoda: Pulmonata). Oceanogr Mar Biol Annu Rev 37: $245-288$ 
Jaksic FM (1982) Inadequacy of activity time as niche difference: the case of diurnal and nocturnal raptors. Oecologia 52:171-175

> Jenkins SR, Coleman RA, Della Santina P, Hawkins SJ, Burrows MT, Hartnoll RG (2005) Regional scale differences in the determinism of grazing effects in the rocky intertidal. Mar Ecol Prog Ser 287:77-86

$>$ Johnson MP, Hanley ME, Frost NJ, Mosley MWJ, Hawkins SJ (2008) Persistent spatial patchiness of limpet grazing. J Exp Mar Biol Ecol 365:136-141

Legendre P, Fortin MJ (1989) Spatial pattern and ecological analysis. Plant Ecol 80:107-138

Legendre P, Galzin R, Harmelin-Vivien M (1997) Relating behavior to habitat: solutions to the fourth-corner problem. Ecology 78:547-562

> Levings SC, Franks NR (1982) Patterns of nest dispersion in a tropical ground ant community. Ecology 63:338-344

Lindberg DR (2007) Reproduction, ecology, and evolution of the Indo-Pacific limpet Scutellastra flexuosa. Bull Mar Sci 81:219-234

Little C (1989) Factors governing patterns of foraging activity in littoral marine herbivorous molluscs. J Molluscan Stud 55:273-284

López-Gappa J, Tablado A, Magaldi N (1996) Observations on activity pattern and resting site fidelity in the pulmonate limpet Siphonaria lessoni. Thalassas 12:27-36

Loreau M (1992) Time scale of resource dynamics and coexistence through time partitioning. Theor Popul Biol 41: 401-412

Lubchenco J, Gaines SD (1981) A unified approach to marine plant-herbivore interactions. I. Populations and communities. Annu Rev Ecol Syst 12:405-437

Manly BFJ (1997) The design and analysis of research studies. Cambridge University Press, Cambridge

Marshall D, McQuaid C (1991) Metabolic rate depression in a marine pulmonate snail: pre-adaptation for terrestrial existence? Oecologia 88:274-276

Marshall D, McQuaid C (1994) Seasonal and diel variations of in situ heart rate of the intertidal limpet Siphonaria oculus Kr. (Pulmonata). J Exp Mar Biol Ecol 179:1-9

McQuaid C, Froneman P (1993) Mutualism between the territorial intertidal limpet Patella longicosta and the crustose alga Ralfsia verrucosa. Oecologia 96:128-133

Ng JSS, Williams GA (2006) Intraspecific variation in foraging behaviour: influence of shore height on temporal organization of activity in the chiton Acanthopleura japonica. Mar Ecol Prog Ser 321:183-192

> Olabarria C, Underwood AJ, Chapman MG (2002) Appropriate experimental design to evaluate preferences for microhabitat: an example of preferences by species of microgastropods. Oecologia 132:159-166

Oliva D, Castilla JC (1986) The effects of human exclosure on the population structure of key-hole limpets Fissurella crassa and Fissurella limbata in the coast of Central Chile. PSZN I: Mar Ecol 7:201-217

Olivier SR, Penchaszadeh PE (1968) Observaciones sobre la ecología y biología de Siphonaria lessoni (Blainville, 1824) (Gastropoda: Siphonariidae) en el litoral rocoso de Mar del Plata (Buenos Aires). Cah Biol Mar 9:469-491

Otaíza RD, Santelices B (1985) Vertical distribution of chitons (Mollusca: Polyplacophora) in the rocky intertidal zone of central Chile. J Exp Mar Biol Ecol 86:229-240

Editorial responsibility: Roger Hughes, Bangor, UK
Palmer JD (1995) The biological rhythms and clocks of intertidal animals. Oxford University Press, Oxford

Pielou EC (1961) Segregation and symmetry in two-species populations as studied by nearest neighbour relationships. J Ecol 49:255-269

Polis GA, Holt RD (1992) Intraguild predation: the dynamics of complex trophic interactions. Trends Ecol Evol 7: $151-154$

Pulliam R (1989) Individual behavior and the procurement of essential resources. In: Roughgarden J, May R, Levin S (eds) Perspectives in ecological theory. Princeton University Press, Princeton, NJ, p 383

Rivadeneira MM, Fernández M, Navarrete SA (2002) Latitudinal trends of species diversity in rocky intertidal herbivore assemblages: spatial scale and the relationship between local and regional species richness. Mar Ecol Prog Ser 245:123-131

Rossi RE, Mulla D, Journel AG, Franz EH (1992) Geostatistical tools for modeling and interpreting ecological spatial dependence. Ecol Monogr 62:277-314

Santelices B, Vásquez J, Meneses I (1986) Patrones de distribución y dietas de un gremio de moluscos herbívoros en habitats intermareales expuestos de Chile central. In: Santelices B (ed) Monografías Biológicas Simposio Internacional Usos y funciones de las algas marinas bentónicas, Vol 4. Pontificia Universidad Católica de Chile, Santiago, p $147-171$

Schmitz OJ (2008) Herbivory from individuals to ecosystems. Annu Rev Ecol Evol Syst 39:133-152

Schoener TW (1983) Field experiments on interspecific competition. Am Nat 122:240-285

- Serra G, Castilla JC, Chelazzi G (2001) Temporal and spatial activity of the key-hole limpet Fissurella crassa (Mollusca: Gastropoda) in the eastern Pacific. J Mar Biol Assoc UK 81:485-490

Sokal RR, Oden NL (1978) Spatial autocorrelation in biology. 1. Methodology. Biol J Linn Soc 10:199-228

Steneck RS, Watling L (1982) Feeding capabilities and limitation of herbivorous molluscs: a functional group approach. Mar Biol 68:299-319

Stimson J (1970) Territorial behaviour of the owl limpet Lottia gigantea. Ecology 51:113-118

Tilman D, Kareiva P (1997) Spatial ecology: the role of space in population dynamics and interspecific interactions. Princeton University Press, Princeton, NJ

> Underwood AJ (1976) Nearest neighbour analyses of spatial dispersion of intertidal prosobranch gastropods within two substrata. Oecologia 26:257-266

Underwood AJ, Chapman MG (1996) Scales of spatial patterns of distribution of intertidal invertebrates. Oecologia $107: 212-224$

- Webb C, Ackerly D, McPeek M, Donoghue M (2002) Phylogenies and community ecology. Annu Rev Ecol Syst 33: 475-505

> Wieters EA, Kaplan DM, Navarrete SA, Sotomayor A, Largier J, Nielsen KJ, Véliz F (2003) Alongshore and temporal variability in chlorophyll a concentration in Chilean nearshore waters. Mar Ecol Prog Ser 249:93-105

Williams G, Morritt D (1991) Patterns of foraging in Patella vulgata (L.). In: Myers ALC, Costello M, Partridge J (eds) The ecology of Lough Hyne. Royal Irish Academy, Dublin, p 61-69

Submitted: August 18, 2010; Accepted: February 23, 2011

Proofs received from author(s): May 31, 2011 